\title{
Sejarah Berdirinya Perguruan Tinggi 'Aisyiyah (PTA) di Indonesia
}

\author{
Iwan Setiawan ${ }^{1^{*}}$, Muhammad Ichsan Budi Prabowo ${ }^{1}$ \\ 1 Universitas Aisyiyah Yogyakarta, Indonesia \\ ${ }^{2}$ Kurator Museum Muhammadiyah, Universitas Ahmad Dahlan Yogyakarta, Indonesia \\ *Korespondensi: iwan@unisayogya.ac.id
}

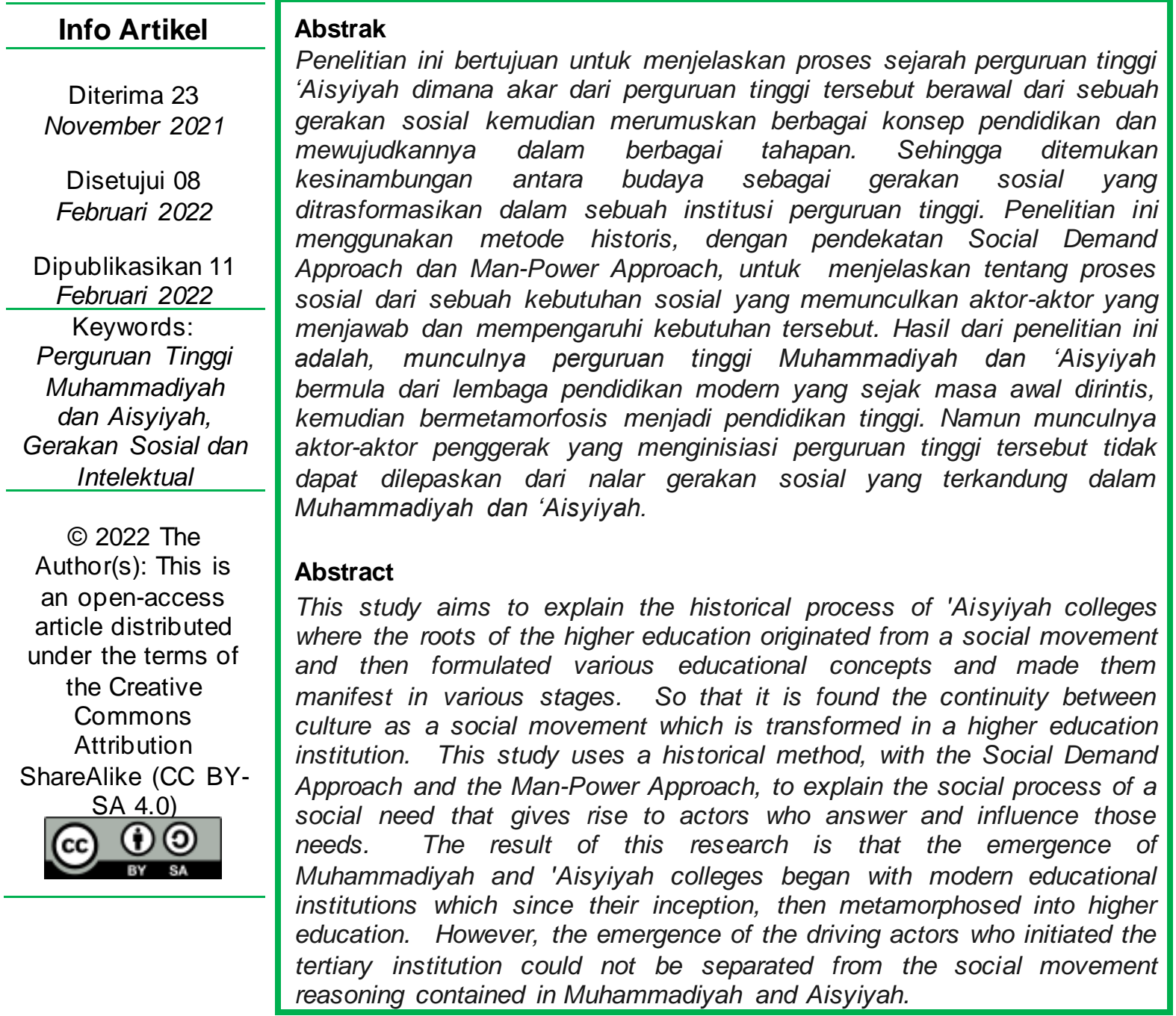

\section{Pendahuluan}

Muhammadiyah tidak sekedar menjadi gerakan pembaruan Islam, namun melintasi perkembangan zaman. la bermetamorfosis menjadi sebuah sub kebudayaan Islam Indonesia. Muhammadiyah melahirkan budaya pergerakan 
yang kritis dan terbuka, budaya politik yang bijak serta adil, dan tentunya sebuah budaya pendidikan yang mana dari sini akar dan ruh Muhammadiyah berada. Memahami konteks pendidikan tinggi Muhammadiyah tidak dapat dilepaskan dari akar sejarah pendidikan Muhammadiyah secara utuh baik peristiwa historis maupun falsafah dasar yang terbentuk sejak awal masa pendiriannya (Arifin, 1987).

Menurut Djindar Tamimy, dalam diri KH. Ahmad Dahlan memiliki kesadaran untuk mengubah sesuatu yang tidak tepat. sehingga berdirinya Muhammadiyah pada 1912 merupakan hal yang progresif pada masanya (Nashir, 2019). Yang menarik cara dan gaya $\mathrm{KH}$. Ahmad Dahlan dalam menyampaikan gagasannya beliau sangat akrab dengan lingkungan. Keakraban ini didasarkan atas kesadaran $\mathrm{KH}$. Ahmad Dahlan tentang dirinya di tengah lingkungan Kauman. Sehingga meskipun beliau menerobos tatanan lingkungan masyarakat namun beliau menyadari posisinya sebagai seorang abdi dalem Kraton Yogyakarta. Dalam hal ini gagasannya mengenai pembaruan Islam tidak pernah menyerang personal melainkan hanya mengemukakan pemikiran alternatif pada masanya. Walaupun apa yang dilakukan KH Ahmad Dahlan dalam mengubah sesuatu tidak mudah, karena berkaitan dengan mengkritik pelaksanaan praktek keagamaan yang su dah turun temurun (Jainuri, 2002).

Ahmad Syafii Maarif menjelaskan jika seorang Muslim terpengaruh dengan ide yang progresif pada masa itu, maka jalannya adalah dengan kembali kepada pada sumber ajaran Islam yang otentik kemudian dipadukan ide-ide progresif yan $g$ berasal dari Barat (Qodir and Nashir, 2019). Ide-ide progresif yang ditransformasikan pada gerakan Muhammadiyah dan pendidikan Muhammadiyah berangkat dari kondisi umat pada masa itu yang mengalami kejumudan/terbelakang. Meskipun kejumudan bukanlah sebuah pengingakaran pada Al Qur'an, namun menurut para pembaharu di masa itu, hal tersebut merupakan bentuk pengingkaran terhadap tujuan Islam sebagai rahmatan lil alamin (Maarif, 1985)

Dengan demikian Muhammadiyah segera mengalami perkembangan yang pesat sejak dekade pertama kelahirannya. Semangat untuk memajukan Islam lewat gerakan sosial dan persuratkabaran kemudian di rawat dengan pendidikan menjadi menjadi jantung Muhammadiyah. Ketiga hal tersebut yang oleh Taufik Abdullah (Abdullah, 1996) dinilai menjadi keunggulan penting Muhammadiyah dibanding gerakan Islam lainnya di Indonesia. Keberadaan lembaga pendidikan dalam tubuh Muhammadiyah selain menjadikan gerakan ini lekas berkembang namun juga ia menjadi ujung tombak agar gerakan ini tetap dinamis dan senantiasa memperbarui dirinya (Ridwan, 2021). Hingga tahun 1920 Muhammadiyah telah membentuk empat bagian yang mewakili tiap bidang yaitu; Bahagian Pendidikan, bahagian PKO, Bahagian Taman Pustaka, dan Bahagian Tabligh. Selain itu sayap gerakan Muhammadiyah telah meluas kepada bidang kepanduan dengan membentuk Hizbul Wathan dan Aisyiyah sebagai gerakan perempuan.(Mu'ti, 2016)

\section{Metode Penelitian}

Penelitian ini menggunakan metode sejarah (historical methods), yaitu seperangkat aturan dan prinsip sistematis untuk mengumpulkan sumber-sumber sejarah secara efektif, menilainya secara kritis dan mengajukan sintesis dari hasilhasil yang dicapai dalam bentuk tertulis dalam perspektif sejarah(Dudung 
Abdurrahman, 2011). Dalam metode sejarah ini menggunakan langkah-langkah yaitu, pengumpulan data (heuristic), kritik sumber (verifikasi), penafsiran (interpretasi) dan penulisan sejarah (historiografi). Penulisan ini sifatnya deskripstif dan jenisnya library research. Dalam library research hal yang paling penting berkaitan dengan sumber sumber sejarah, yang berasal dari dokumen, buku, artikel jurnal dll. Berkaitan dengan sumber sejarah perlu juga melakukan verifikasi dengan cara membandingkan dengan sumber lain, sehingga mendapatkan data yang valid(Bondan Kanumoyoso, 2020). Penelitian ini fokus pada masa pendirian Perguruan Tinggi Muhammadiyah dan Aisyiyah.

\section{Hasil dan Pembahasan}

\subsection{Gagasan Awal Perguruan Tinggi}

Proses inisiasi pendirian perguruan tinggi dalam pemikiran para perintis Muhammadiyah dimulai dari sebuah pertemuan resmi Hoofdbestur (HB) Muhammadiyah pada malam 17 Juni 1920 di Suronatan. Pertemuan tersebut pada dasarnya merupakan respon dari terbitnya surat Government yang menyatakan bahwa Muhammadiyah secara resmi menjadi gerakan yang dapat mengembangkan cabangnya diseluruh Hindia-Belanda sekaligus peresmian bagian-bagian yang ada dalam struktur pimpinan beserta laporan dan target yang ingin dicapai tiap-tiap bagian tersebut.(Nashir, 2019)

Rapat besar tersebut dipimpin oleh $\mathrm{KH}$. Ahmad Dahlan sebagai ketua yang membuka sidang dengan mempersilahkan tiap-tiap bahagian memberikan laporannya (I. S. Setiawan, 2018). Dalam catatan yang ditulis oleh Muhammad Suja' menyebutkan sebagai berikut; Pertama kali yang diberikan kesempatan berpidato dan dilantik yaitu $\mathrm{KH}$ M. Hisyam dari bahagian pengajaran, $\mathrm{KH}$. Ahmad Dahlan membuka dengan mengajukan pertanyaan, "Sampai kemana bahagian pengajaran/sekolah akan mendirikan sekolahnya" Saudara KH Hisyam menjawab dengan suci murni dan hati-hati menyatakan bahwa "Saya akan membawa kawan kawan kita pengurus bahagian pengajaran berusaha memajukan pendidikan dan pengajaran sampai dapat menegakkan gedung universiteit Muhammadiyah yang megah, untuk mencetak sarjana-sarjana Islam dan mahaguru-mahaguru Muhammadiyah pada khususnya dan guna kepentingan Islam pada umumnya"(Sudja, 2020) Jawaban ini mendapat sambutan baik dari KH Ahmad Dahlan, dengan mengucap Alhamdulillah yang diiringi tepuk tangan pada hadirin. Hal yang dikemukakan oleh KH Hisyam bukannya tanpa alasan dan pengalaman, pada masa tersebut memang politik etis cukup berhasil bagi pemerintah kolonial, namun kenyataannya hasil pendidikan bagi pribumi tetap menempatkan mereka pada status yang tidak adil.

$\mathrm{KH}$ Hisyam menjadi inisiator pendidikan Muhammadiyah secara umum dan mewariskan kunci penting bagi lahirnya perguruan tinggi Muhammadiyah yang meski baru dimulai empat dekade kemudian. Kepemimpinan K.H. Hisyam menonjol dalam hal manajemen, administrasi organisasi, dan pendidikan. Pendidikan baginya merupakan usaha peningkatan kualitas sumber daya manusia. Kalau pendidikan maju, maka umat Islam juga akan maju. Maka pola pendidikan Muhammadiyah harus diubah Pada periode ini, telah dibuka sekolah dasar/volkschool atau sekolah desa) dengan kurikulum dan syarat-syarat volkschool guberne. K.H. Hisyam memang berusaha keras untuk memajukan pendidikan di kalangan Muhammadiyah. Dalam usaha ini, beliau bekerja sama 
dengan pemerintah Belanda antara lain bersedia menerima bantuan keuangan dari Belanda. Hal inilah yang sering menjadi bahan kritikan dari Taman Siswa dan Syarikat Islam. Kedua kelompok ini pada waktu itu sedang gencar-gencarnya melontarkan politik non-kooperatif dengan pemerintah Belanda. Sedangkan Muhammadiyah memilih pada Gerakan kultural dengan mendirikan sekolah (Burhani, 2019)

Hal yang dilakukan oleh Muhammadiyah dalam sikap kooperatif K.H. Hisyam sejatinya tidaklah mudah. Sebagai organisasi dengan ruh kemerdekaan dan sekaligus Islam tentunya sikap bekerja sama dengan pemerintah kolonial bertentangan dengan tujuan awalnya (Shihab, 2018). Namun dalam pandangan Muhammadiyah maslahat yang lebih besar untuk umat dalam aspek yang mendasar harus tetap dicapai apapun risiko dan kesulitannya. Sementara langka $h$ non kooperatif membawa dan resisten besar terhadap gerakan zending dan misionaris justru tengah menyulitkan gerakan nasional lainnya, Muhammadiyah justru merepelika gerakan tersebut, dengan membalik makna sepenuhnya untuk kepentingan umat dan bangsa Indonesia (Qodir and Jubba, 2021).

Pada kenyataannya kerjasama Muhammadiyah dengan pemerintah kolonial dalam bidang pendidikan dan kesehatan jauh memberikan manfaat bagi perkembangan pendidikan dan aktivitas kesehatan yang dilakukannya, sehingga dalam pandangan pemerintah dan masyarakat Hindia Belanda pada masa itu Muhammadiyah menjadi organisasi modern yang benar-benar diperhitungkan (Nashir, 2013). Kekuatan pendidikan Muhammadiyah dengan demikian telah Iama menjadi sebuah nilai tawar yang kuat dihadapat berbagai otoritas disekitarnya, hal ini lah yang kemudian menjadi modal penting bagi Muhammadiyah untuk terus membangun sistem dan jaringan pendidikan yang baik dan terkoordinir. Maka, berdasarkan pada kekuatan sersebut sekiranya kelairan perguruan tinggi sebenarnya hanya merupakan sebuah tah apan dalam penyempurnaan pendidikan di Muhamadiyah (Zarro, 2020).

\subsection{Embrio Perguruan Tinggi Aisyiyah (PTA)}

Pendidikan kemudian menjadi salah satu muara penting dalam dakwah Muhammadiyah (Alifuddin, 2021). Hal ini yang ditegaskan oleh Ki Bagus Hadikusumo selaku Ketua Pimpinan Pusat Muhammadiyah buah dari Muktamar ke 31 tahun 1950. Memang di akui pendidikan yang sebelumnya menjadi motor penggerak Muhammadiyah cukup morat-marit pasca revolusi, hal ini tidak hanya diakibatkan karena perubahan tatanan sosial pasca revolusi. Namun perpecahan politik juga mengalami dampaknya baik secara langsung maupun tidak langsung.

Konflik antara Masyumi dan NU sebagai partai politik menyeret Muhammadiyah, pada gejala masyarakat sangat beragam baik terjadi akomodasi kalangan modernis terdapat tradisionalis untuk kepentingan politiknya maupun sebaliknya, kemudian pada tataran elit perebutan kursi kabinet dan pergantian menteri yang tidak teratur menjadikan kebijakan sukar untuk dijalankan secara baik dan maksimal (Alfian, 1996). Berdasarkan kondisi tersebut setidaknya terdapat tiga tantangan Muhammadiyah dalam mengembangkan kembali pendidikannya pasca kemerdekaan. Pertama, penyempurnaan kembali struktur Muhammadiyah baik ditingkat atas maupun bawah serta setiap bahagian didalamnya, Kedua, penyesuaian dengan lembaga pendidikan Muhammadiyah dengan kementerian pendidikan atau pun kementerian agama, di samping tetap 
berusaha untuk mempertahankan kemandiriannya. Ketiga, tantangan pendidikan Muhammadiyah untuk menjawab tantangan zaman yang cepat berubah baik secara moral maupun material.

Kemerdekaan pada kenyataannya menunjukkan kesempatan yang cukup singnifikan bagi bangsa Indonesia untuk menyempurnakan pendidikannya. Seiring meningkatnya keamanan dalam negeri Indonesia pasca tahun 1950, maka Muhammadiyah kembali secara maksimal dapat mewujudkan program pendidikan yang telah direncanakannya. Maka diadakan Konferensi Pendidikan Muhammadiyah di Bandung pada tahun 1954, Konferensi tersebut membuahkan dua usulan yang disampaikan dalam Tanwir tahun berikutnya yaitu Supaya Pimpinan Pusat Muhammadiyah menugaskan kepada Majelis pendidikan dan pengajaran pusat untuk menyelenggarakan Universitas Muhammadiyah (Suara Muhammadiyah, 1954)

Sebelum hasil dan rekomendasi dari Konferensi Pendidikan Muhammadiyah di Bandung pada tahun 1954 diajukan ke Tanwir yang baru dilaksanakan setahun setelahnya, Muhammadiyah bagian Sumatera Tengah telah terlebih dahulu menyelenggarakan konferensi daerah. Konferensi Muhammadiyah Sumatra Tengah diselenggarakan di Lubuk Alung pada tanggal 19-23 Maret 1954. Konferensi ini berhasil memutuskan untuk mendirikan sebuah perguruan tinggi dengan permulaan pembentukan Fakultas Falsafah dan Hukum yang berlokasi di Kompleks Perguruan Muhammadiyah Kauman Padang Panjang, secara praktis maka inilah universitas yang pertama kali didirikan oleh Muhammadiyah (I. Setiawan, 2020).

Kemunculan Perguruan Tinggi Aisyiyah (PTA) pada dasarnya merupakan karakter dari pendidikan Muhammadiyah yang tumbuh dari bawah dan kemudian terus membangun hingga ketingkatan selanjutnya. Perkembangan PTA kemu dian juga memberi warna yang singnifikan dalam perkembangan pendidikan Muhammadiyah. Eksisnya pendidikan Muhammadiyah menjadi bukti jika ruh pendidikan Muhammadiyah sejatinya bersifat universal dan washatiyah (Qodir, 2019) kemudian dapat secara fleksibel beradaptasi dengan berbagai model keislaman yang ada di berbagai daerah.

\subsection{Berdirinya Perguruan Tinggi Aisyiyah (PTA)}

Memahami karakter PTA perlu kita menarik jauh ke belakang dari bagaimana Aisyiyah sebagai gerakan perempuan Islam modern memandang penting arti sebuah kesehatan. Dimulai jauh dari zaman awal dirintisnya Aisyiyah pada awal abad ke 20. Sejak awal pendiriannya, Aisyiyah telah menaruh perhatian besar pada kesehatan masyarakat khususnya kesehatan perempuan. Menurut Van der Kwaak kesehatan perempuan merupakan kesejahteraan secara total yang berati tidak hanya ditentukan oleh faktor biologis dan reproduktif namun juga dipengaruhi oleh faktor beban kerja, gizi, stres, perang, migrasi, dan lain sebagainya (M. A. Koblinsky, 1997). Dapat disimpulkan bahwa peningkatan kesehatan perempuan tidak terbatas pada pengobatan gangguan kesehatan namun juga harus memperbaiki lingkungan hidupnya agar perempuan memiliki kendali atas kesehatan mereka sendiri.

Pandangan jika usaha kesehatan bagi perempuan hanya dapat optimal melalui sebuah edukasi kesehatan pada dasarnya telah dirintis sejak tahun 1930 dengan program Muballighat kesehatan. Kursus Muballighat berguna untuk 
meningkatkan kuantitas dan kualitas motivator kesehatan masyarakat melalui pelatihan, diskusi, dan kegiatan lain yang menunjang dakwah Aisyiyah di bidang kesehatan. Hal ini serupa dengan usulan dari $\mathrm{Ng}$. Soetarjo dalam Preadvies Kongres ke-28 Muhammadiyah tahun 1939 berikut.

Soepaja Moebalighot mempeladjari hal oeroesan bersalin dan boekoe-boekoe; lebih baik poela kalau Tjabang-tjabang dan Groep-groep mengadakan Cursus, goeroenya seorang jang ahli tentang hal itoe (Suara Muhammadiyah, 1939)

Kursus untuk para muballighat ini sangat menentukan kecakapan mereka saat bertugas di lapangan sehingga dapat dikatakan program Aisyiyah yang ditujukan kepada masyarakat telah dipikirkan matang-matang baik dari sisi Sumber Daya Manusia (SDM) maupun sarana dan prasarananya. Menjelang tahun 1940 Aisyiyah semakin mengerucutkan pandangan jika pendidikan kesehatan merupakan saluran utama dalam upaya memperbaiki kesehatan masyarakat. Maka dengan demikian kader-kader muda yang tugs untuk mewujudlan cita-cita tersebut hanya dapat dibentuk melalui lahirnya sebuah lembaga pendidikan tinggi dibidang kesehatan. Menurut hasil Kongres Muhammadiyah ke-28 tahun 1939 di Medan, Nasyiatul Aisyiyah akan diberikan pengajaran tentang perawatan orang sakit dan kebidanan (Muhammadiyah, 1939). Dalam kongres tersebut, Siti Badilah Zuber menyampaikan idenya tentang pengadaan Constantiebureau yaitu, min imal satu di setiap daerah untuk melayani pemeriksanaan ibu yang hendak bersalin dan pemeriksaan bayi.

Abu Hanifah, Seorang dokter Muhammadiyah Sumatra Barat menyarankan agar Constantiebureau milik Aisyiyah meminta bantuan dokter atau perawat yang tersedia di setiap wilayah dan menjalin kerja sama dengan perkumpulanperkumpulan sosial lain. Menurut Abu Hanifah peran zending sangat mendominasi dalam memperhatikan kesehatan masyarakat, beliau ingin umat Islam bangkit untuk mengusahakan kesehatan masyarakat juga (Jainuri, 1981). Dapat disimpulkan bahwa usaha keras Aisyiyah untuk meningkatkan kesehatan masyarakat didorong oleh semangat menegakkan ajaran agama Islam dan sebagai oposisi pihak zending pada khususnya dan menyempurnakan kehidupan umat pada umumnya.

Jaringan Aisyiyah juga menjadi modal dalam pembangunan PTA, meskipun dari sisi kuantitas lembaga pendidikan yang secara mandiri dikelola oleh Aisyiyah tidak sebanyak Muhammadiyah, namun potensi sebagai gerakan perempuan Islam terbesar menepatkannya pada posisi yang strategis. Pelayanan terhadap perempuan kemudian menjadi dasar awal dari pengembangan perguruan tingginya.

Dimulai dari tahun 1954 dengan dibukanya Sekolah Bidan dari lulusan SMP, usia minimal 17 tahun, dengan lama pendidikan 3 tahun. Selain itu, untuk memenuhi kebutuhan akan tenaga kesehatan yang semakin banyak dan memerlukan keahlian menolong persalinan, maka dibuka lagi pendidikan pembantu bidan yang disebut Penjenang Kesehatan E (PK-E). Sekolah PK-E ini diperuntukkan para lulusan SMP dan menempuh studi kebidanan dasar selama 2 tahun (Majelis Pustaka dan Informasi, 2017). Lulusan PK-E dapat melanjutkan ke sekolah bidan dengan menambah pendidikan kebidanan selama 2 tahun. Selain pendidikan kebidanan, juga diselenggarakan sekolah guru bidan, guru perawat, dan perawat kesehatan masyarakat di Bandung pada tahun 1954. Pada awalnya, 
hanya berlangsung selama 1 tahun, akan tetapi kemudian mengalami perkembangan menjadi 2 tahun, dan terakhir selama 3 tahun

Pendirian PTA kemudian mendapat sorotan dalam Muktamar Muhammadiyah setengah abad tahun 1962 di Jakarta. Sebagai wacana A. Kahar Muzakir dalam muktamar kerja Aisyiyah menerangkan:

Sebenarnya masalah kelanjutan Madrasah Mu'allimat itu bukanlah masalah baru dan bukan pula masalah yang belum pernah dilaksanakan. Akan tetapi adalah masalah lama dan sudah pernah dilaksanakan dengan nama Takhasus artinya spesialisasi untuk memperdalam sesuatu mata ilmu dalam sesuatu perguruan tinggi. Takhasus telah diadakan beberapa tahun dahulu dalam rangka madrasah Mu'allimat sendiri.(Abdul Munir Mulkhan, 1990)

Menurut A. Kahar Muzakir perguruan tinggi yang berasal dari Madrasah Mu'allimat ini sebenarnya sebagai yang diharapkan adalah suatu universitas wanita berdasar Islam. Universitas inilah di kemu dian hari sebaiknya menjadi suatu universitas yang lengkap dalam bidang-bidang keahlian yang sesuai dengan sifatsifat wanita. Pendidikan Tenaga Kesehatan 'Aisyiyah disepakati untuk dibuka dan menjadi salah satu keputusan Muktamar 'Aisyiyah ke-35 di Jakarta. Penyelenggaraannya bekerjasama dengan Rumah Sakit Umum PKU Muhammadiyah di Yogyakarta. Karena itu, sekolah ini sering disebut Sekolah Bidan 'Aisyiyah RSU-PKU Muhammadiyah Yogyakarta. Keputusan untuk mendirikan dan menyelenggarakan sekolah ini kemudian diperkuat dengan Surat Keputusan Menteri Kesehatan RINomor 65 tanggal 10 Juli 1963.

Muhammadiyah pada awal berdirinya fokus pada program feeding, healing dan educating atau pelayanan sosial, pelayanan kesehatan dan pelayanan pendidikan(Nashir and Jinan, 2019). Aisyiyah sebagai organisasi perempuan Muhammadiyah menjawabnya dengan mendirikan Sekolah Bidan Aisyiyah di Yogyakarta pada 10 Juli 1963 lalu berganti menjadi Sekolah Panjenang Kesehatan Tingkat C Rumah Sakit PKU Muhammadiyah Yogyakarta dengan membuka prodi Kebidanan dan Keperawatan. Tahun 1978 Sekolah Panjenang Kesehatan menjadi Sekolah Perawat Bidan Aisyiyah (SPB A),tahun 1991 berubah menjadi Akademi Keperawatan (AKPER) Aisyiyah lalu menjadi Akademi Kebidanan (AKBID) Aisyiyah Yogyakarta.

Tahun 2003 AKBID Aisyiyah Yogyakarta menginduk ke Kementerian Pendidikan dan Kebudayaan dan bukan lagi ke Kementerian Kesehatan. Maka nama Sekolah Tinggi IImu Kesehatan (STIKES) Aisyiyah Yogyakarta menjadi pilihannya. Keinginan kuat untuk menjadikan STIKES Aisyiyah menjadi Universitas memacu STIKES Aisyiyah untuk berbenah dan mendaftar menjadi Universitas. Setelah menunggu bertahun-tahun Pada 11 Maret 2016 Kementerian Ristek Dikti menyerahkan ijin perubahan STIKES Aisyiyah Yogyakarta menjadi Universitas Aisyiyah Yogyakarta (UNISA) Yogyakarta (Majelis Pustaka dan Informasi, 2017).

Perjalanan panjang pendirian Perguruan Tinggi Muhammadiyah (PTM) di Padang Panjang tahun 1954 dan Perguruan Tinggi Aisyiyah (PTA) di Yogyakarta pada 1963 adalah bukti Muhammadiyah memiliki vitalitas dalam membangun perguruan tinggi. : 
Tabel 1. Data Perguruan Tinggi Muhammadiyah dan Aisyiyah tahun 2019

\begin{tabular}{lllll}
\hline No & Bentuk & PTM & PTA & Jumlah \\
\hline 1 & Akademi & 10 & 2 & 12 \\
\hline 2 & Politeknik & 4 & 1 & 5 \\
\hline 3 & Sekolah Tinggi & 97 & 2 & 100 \\
\hline 4 & Institut & 5 & 0 & 5 \\
\hline 5 & Universitas & 47 & 3 & 50 \\
\hline & Jumlah Total & 163 & 8 & 171 \\
\hline
\end{tabular}

Sumber: (Majelis Diktilitbang Pimpinan Pusat Muhammadiyah, 2019)

Perkembangan PTM memang lebih laju dari pada perkembangan PTA. PTM mengelola 163 perguruan tinggi dan PTA mengelola 8 perguruan tinggi (Majelis Diktilitbang PP Aisyiyah, 2021). Menurut Sulistyaningsih, Wakil Sekretaris Majelis Pendidikan Tinggi Pimpinan Pusat Aisyiyah ( Majelis DIKTI PPA) Hal ini dapat terjadi karena Aisyiyah dalam pengembangan pendidikan lebih fokus pada pendidikan anak usia dini (PAUD) dibandingkan dengan pengembangan PTA (Wawancara 15 Agustus 2020). Di awal abad 21 Aisyiyah mulai memaksimalkan peranan Majelis Dikti PP Aisyiyah untuk fokus pada pengembangan PTA. Perubahan STIKES Aisyiyah Yogyakarta menjadi UNISA Yogyakarta juga memacu PTA lain untuk berkembang. Belum lama ini STIKES Aisyiyah Surakarta berubah menjadi UNISA Surakarta. Selanjutnya disusul oleh STIKES Aisyiyah Bandung menjadi UNISA Bandung. Tentu perubahan 3 PTA menjadi Universitas adalah kemajuan yang perlu diapresiasi.

Sulistyaningsih juga menjelaskan usaha untuk mengembangkan Pen didikan Tinggi di Aisyiyah terus dilakukan saat ini. Berubahnya STIKES Aisyiyah Yogyakarta dan diikuti oleh Surakarta dan Bandung menjadi Universitas memacu Pimpinan Pusat Aisyiyah untuk mengembangkan Perguruan Tinggi yang menjadi binaan Aisyiyah. Perubahan orientasi Pimpinan Pusat Aisyiyah yang bukan hanya fokus pada pengembangan PAUD, tetapi juga Perguruan Tinggi merupakan tantangan tersendiri dalam mengembangkan amal usaha Aisyiyah.

Dalam sejarahnya, PTA didirikan oleh Aisyiyah tingkat wilayah atau daerah. Hanya UNISA Yogyakarta yang langsung didirikan oleh Pimpinan Pusat Aisyiyah. Sehingga dinamika pengembangan tiap PTA tergantung kepada wilayah dan daerah Aisyiyah yang mengelola PTA. Pengembangan PTA berarti juga meluaskan lahan dakwah di bidang Pendidikan bagi Aisyiyah. Sehingga membangun kualitas PTA menjadi penting. Salah satu ukuran kualitas PTA dapat dilihat dari klaster penelitian dan pengabdian di pergu ruan tinggi yang dikeluarkan oleh Kemendikbud Ristes, apakah masuk binaan, madya dan mandiri atau belum masuk klaster. Di tahun 2022 bertambah 1 PTA sehingga ada 9 PTA yang dikelola Majelis Dikti PPA dengan klaster penelitian dan pengabdian masyarakat.

Tabel 2. Jumlah PTA Tahun 2022

\begin{tabular}{lll}
\hline No & \multicolumn{1}{c}{ Kampus } & $\begin{array}{c}\text { Klaster Penelitian dan } \\
\text { Pengabdian } \\
\text { Masyarakat }\end{array}$ \\
\hline 1 & UNISA Yogyakarta & Madya \\
\hline 2 & UNISA Surakarta & Madya \\
\hline 3 & UNISA Bandung & Madya \\
\hline 4 & STIKES Aisyiyah Palembang & Binaan \\
\hline
\end{tabular}




\begin{tabular}{llll}
\hline 5 & STIKES Aisyiyah Riau & Binaan \\
\hline 6 & AKPER Aisyiyah Padang & Binaan \\
\hline 7 & Akbid AISYIYAH Pontianak & Binaan \\
\hline 8 & AKBID Aisyiyah Banten & Binaan \\
\hline 9 & $\begin{array}{l}\text { Institut Sains Teknologi dan } \\
\text { Kendari }\end{array}$ & Kesehatan Aisyiyah & Belum Masuk Klaster \\
\hline
\end{tabular}

Merujuk dari data diatas, pengembangan PTA ke depan perlu mendapat dukungan yang serius dari segenap pihak. Terutama Majelis Dikti PP Aisyiyah dan segenap pengelola PTA harus didorongan untuk mengembangkan PTA. Sejarah membuktikan, Aisyiyah berhasil mengembangkan PAUD dan TK, juga merambah Pendidikan dasar. Pengembangan PTA dapat menjadi lahan untuk meluaskan dakwah Aisyiyah di masa kini dan masa depan, khususnya di bidang Pendidikan yang menjadi trade mark Muhammadiyah.

\section{Kesimpulan}

Sejarah berdirinya Perguruan Tinggi berasal dari kegelisahan aktivis Muhammadiyah dan Aisyiyah dalam melihat perkembangan pendidikan dilingkungan masing-masing. Dari kegelisahan inilah muncul kesadaran sosial untuk membangun Perguruan Tinggi Muhammadiyah dan Aisyiyah (PTMA). Ada keunikan berdirinya PTMA yang diinisiasi oleh organisasi sosial. Sehingga PTMA tumbuh dari bawah, dikembangkan dengan biaya Muhammadiyah dan Aisyiyah. Setelah Perguruan Tinggi Muhammadiyah (PTM) mulai eksis yang menunjukkan kwalitasnya, sekarang giliran Perguruan Tinggi Aisyiyah (PTA) untuk menunjukkan keseriusanya dalam mengembangankan perguruan tingginya. Kemunculan PTA pada dasarnya merupakan karakter dari pendidikan Muhammadiyah yang tu mbuh dari bawah dan kemudian terus membangun menjadi sekarang ini.

\section{Ucapan Terima Kasih}

Penulis mengucapkan terima kasih kepada Lembaga Penelitian dan Pengabdian Masyarakat (LPPM) UNISA Yogyakarta yang memberi kesempatan untuk membahas tema ini. Demikian juga kepada Majelis Pendidikan Tinggi PP Aisyiyah yang memberikan waktunya untuk wawancara dan mendapatkan dokumen yang diperlukan

\section{Daftar Pustaka}

Abdul Munir Mulkhan. (1990). Perkembangan Pemikiran Muhammadiyah dari Masa Ke Masa: Menyambut Muktamar ke-41. Pimpinan Pusat Muhammadiyah.

Ahmad Syafii Maarif. (1985). Studi Tentang Percaturan dalam Konstitusionalisme Islam dan Masalah Kenegaraan. LP3ES.

Alfian. (1996). Muhammadiyah:The Political behaviour of Muslim Modernist Organization Under the Dutch Colonialism. Gadjah Mada Press.

Alifuddin, M. (2021). Muhammadiyah Sebagai Gerakan Pendidikan: Sejarah Eksistensi Perguruan Tinggi Muhammadiyah di Sulawesi Tenggara. A/TA'DIB: Jurnal Kajian IImu Kependidikan, 14(1), 53-74.

Arifin, M. (1987). Gagasan Pembaharuan Muhammadiyah dalam Pendidikan. Pustaka Jaya. 
Bondan Kanumoyoso. (2020). Metode Sejarah. Direktorat Pembinaan Tenaga dan Lembaga Kebudayaan Direktorat Jenderal Kebudayaan Kementerian Pendidikan dan Kebudayaan.

Burhani, A. N. (2019). Muhammadiyah Jawa dan Landasan Kultural Untuk Islam Berkemajuan. Maarif, 14(2), 75-84. https://doi.org/10.47651/mrf.v14i2.63

Dudung Abdurrahman. (2011). Metode Penelitian Sejarah Islam. OMBAK.

Jainuri, A. (1981). Muhammadiyah Gerakan Reformasi Islam Di Jawa Pada Abad Kedua Puluh. Bina llmu.

Jainuri, A. (2002). Ideologi Kaum Reformis. Lembaga Pengkajian Agama dan Masyarakat.

M. A. Koblinsky. (1997). Kesehatan Wanita: Sebuah Perspektif Global. Gadjah Mada Press.

Majelis Diktilitbang Pimpinan Pusat Muhammadiyah. (2019). Direktori Perguruan Tinggi Muhammadiyah dan Aisyiyah. Majelis Diktilitbang PP Muhammadiyah.

Majelis Diktilitbang PP Aisyiyah. (2021). , Sejarah Perkembangan Perguruan Tinggi Aisyiyah. Pimpinan Pusat Aisyiyah.

Majelis Pustaka dan Informasi. (2017). Sejarah Universitas Aisyiyah: Dari Sekolah Menengah Menjadi Perguruan Tinggi,. Majelis Pustaka dan Informasi.

Mu'ti, A. (2016). Akar Pluralisme dalam pendidikan Muhammadiyah. Afkaruna, 12(1), 1-42. https://doi.org/10.18196/aiijis.2016.0053.1-42

Muhammadiyah, S. (1939a). Congres ke-28 Moehammadijah di Medan 19 sd 25 Juli 1939. Suara Muhammadiyah.

Muhammadiyah, S. (1939b). Suara Muhammadiyah. Suara Muhammadiyah.

Muhammadiyah, S. (1954). Konferensi Pendidikan Muhammadiyah di Bandung pada tahun 1954. In Suara Muhammadiyah. Suara Muhammadiyah.

Nashir, H. (2013). Islam Syariat. Suara Muhammadiyah.

Nashir, H. (2019). Indonesia dan Keindonesiaan Perspektif Sosiologis. Suara Muhammadiyah.

Nashir, H., Jinan, M., \& Setiaji, B. (2019). Muhammadiyah: The political behavior of modernist muslim elite in indonesia. Humanities and Social Sciences Reviews, 7(4), 837-844. https://doi.org/10.18510/hssr.2019.74111

Qodir, Z. (2019). Islam Berkemajuan Dan Strategi Dakwah Pencerahan Umat. Jurnal Sosiologi Reflektif, 13(2), 209. https://doi.org/10.14421/jsr.v13i12.1630

Qodir, Z., Jubba, H., Mutiarin, D., \& Hidayati, M. (2021). Muhammadiyah identity and muslim public good: Muslim practices in Java. International Journal of Islamic Thought, 19(1), 133-146. https://doi.org/10.24035/IJIT.19.2021.203

Qodir, Z., \& Nashir, H. (2019). Islamity, Humanity, Indonesianity, and Culture: A Comparative Study on Ahmad Syafii Maarif, Nurcholis Madjid, and Abdurrahman Wahid. Afkaruna, 15(2). https://doi.org/10.18196/aiijis.2019.0104.226-253

Ridwan, M. K. (2021). Jalan Baru Gerakan Moderasi Islam di Indonesia; Reagensi 
Lembaga Pendidikan Muhammadiyah sebagai Basis Gerakan Moderasi. Maarif, 16(1), 60-78. $\quad$ http:/jurnalmaarifinstitute.org/index.php/maarif/article/view/134

Setiawan, I. (2020). Sejarah Majelis Diktilitbang Muhammadiyah. Universitas Muhammadiyah Surakarta.

Setiawan, I. S. (2018). Islam dan Nasionalisme: Pandangan Pembaharu Pendidikan Islam Ahmad Dahlan dan Abdulwahab Khasbullah. Hayula: Indonesian Journal of Multidisciplinary Islamic Studies, 2(1), 1-16. https://doi.org/10.21009/hayula.002.1.01

Shihab, A. (2018). Membendung Arus: Respon Gerakan Muhammadiyah Terhadap Penetrasi Misi Kristen di Indonesia. Suara Muhammadiyah.

Sudja. (2020). Islam Berkemajuan. Suara Muhammadiyah.

Taufik Abdullah. (1996). Agama dan Perubahan Sosial. In Islam dan Masyarakat:Pantulan Sejarah Indonesia. LP3ES.

Zarro, M. (2020). Muhammadiyah Sebagai Gerakan Islam Dan Pendidikan. FACTUM: Jurnal Sejarah dan Pendidikan Sejarah, 9(1), 61-66. https://doi.org/10.17509/factum.v9i1.21503 